\title{
EDITORIAL
}

CrossMark

\& click for updates

\section{Evaluating e-learning concepts: the first ERS interactive online course}

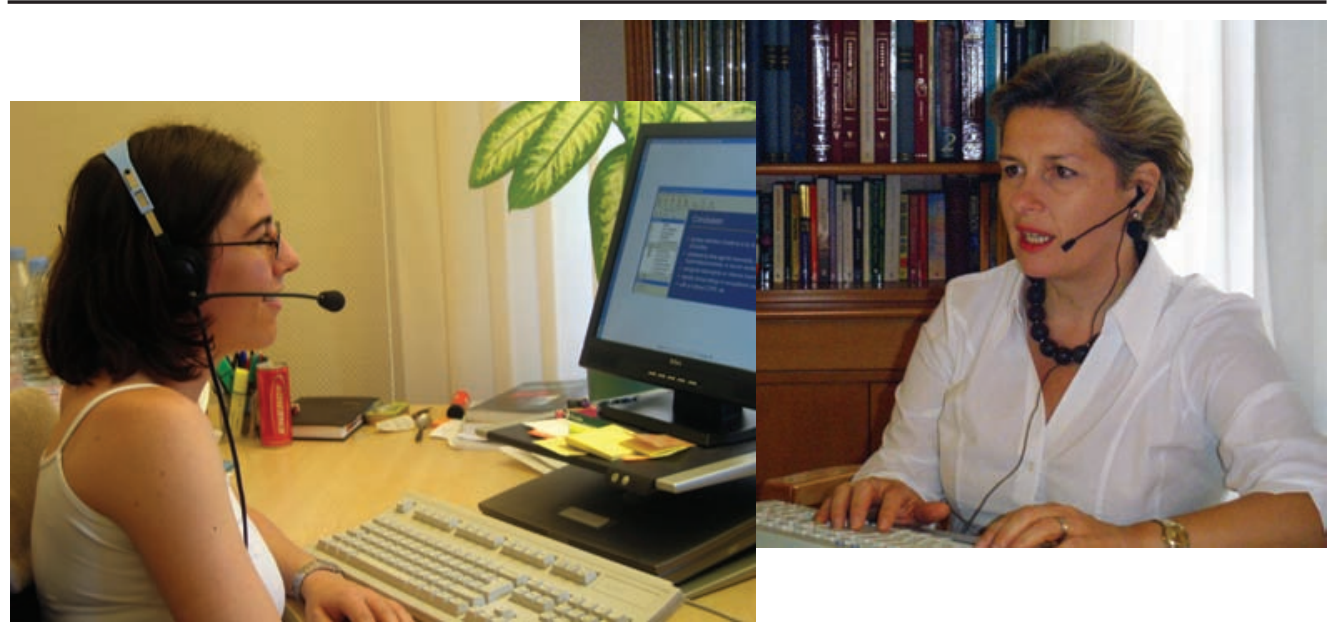

M. Gaga

Director of e-Learning Resources, ERS School

7th Respiratory Medicine Dept and Asthma Centre

Athens Chest Hospital "Sotiria"

Athens

Greece

Fax: 302108000178

E-mail:mgaga@med.uoa.gr

Information technology develops rapidly, as does the potential for elearning. Two examples of the new trends that develop year on year include blended learning and rapid elearning. However, do these new concepts really bring added value to medical education? In order to try to answer this question, the European Respiratory Society (ERS) School has undertaken a two-fold initiative: 1) to identify the preferences of European respiratory specialists and trainees in respiratory medicine with respect to different elearning concepts; and 2) to explore the acceptance of different approaches for web-based teaching. Within this initiative, the interest in three educational approaches was evaluated:

Online live lectures

With this approach, the speaker can make a slide presentation in a similar way to a conference or a classroom presentation. All of the participants can hear the talk given by the presenter and simultaneously see the slides. If a participant's computer is equipped with a microphone, they are also able to ask questions or to discuss with the other participants. Alternatively, they can ask written questions and get a live answer from the presenter. Moreover, this approach gives an opportunity to the presenter to run surveys and polls, allowing them to obtain important feedback, and to gauge the views and thoughts of the audience.

\section{Webcasts}

With this approach, recordings are made during courses or classroom teaching events. The audio from the presenter is then synchronised with the slides and the combination can be played back online. Students can also access the slides and audio commentary separately. Direct interaction between the course participants and the speaker is not possible. However, self-assessment questions at the end of each presentation allow the participants to rate their learning progress.

\section{Interactive text modules}

This approach represents a short aggregation of the current leading academic opinion on a particular topic. Links within the text allow participants to directly access the scientific publication on which the statements are based. Selfassessment questions at the end of the text can again be used to rate an individual's learning progress. These texts are available at any time.

The ERS intends to build up a comprehensive set of web-based courses in respiratory medicine. As a first step, an interactive online course on "Basics in asthma" was developed. The aim of 


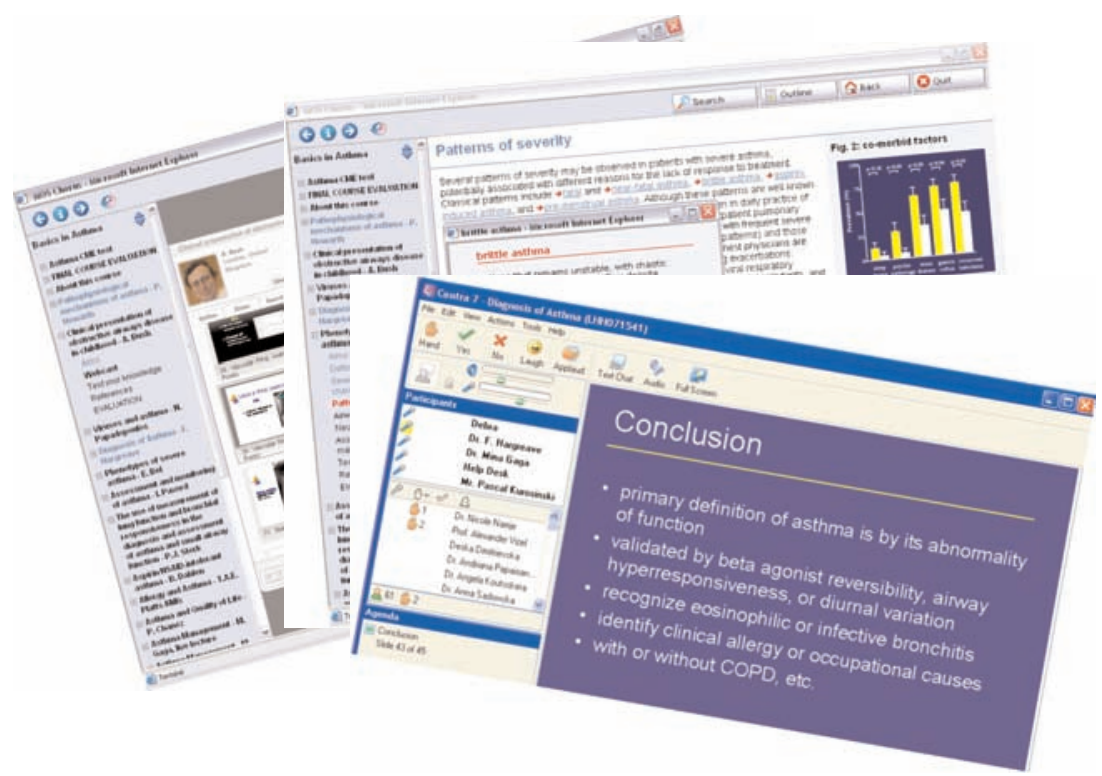

this course was to provide a comprehensive overview of the current internationally accepted definitions of asthma, its diagnosis, pathophysiology and treatment.

The course lasted for 5 weeks, during which 147 participants from 26 countries evaluated 14 different modules. The participants mainly consisted of respiratory physicians (44\%) and trainees in respiratory medicine $(26 \%)$. The mean age of the participants was 37 years. For each module, participants completed a Likertscaled questionnaire, evaluating different aspects of their learning experience.

All three different learning approaches were well received. There was, however, a clear preference for live lectures. Course participants particularly appreciated the possibility to interact directly with the speakers and to instantly obtain expert feedback to specific questions. Conversely, the interactive text modules were used to

satisfaction of cour participants with the three different educational approaches. obtain basic information about the topic and for easy access to more detailed references.

The ERS applied for continuing medical education (CME) accreditation of the course from the European Board of Accreditation in Europe (EBAP) and it was granted. Therefore, this course represents the first distance-learning programme to be accredited by EBAP. For the online live lectures, rules comparable to those used for any normal course were applied, i.e. presence during the event was sufficient to receive CME credits. For the asynchronous parts of the course, the rules were stricter. To obtain CME credits for the webcasts and the interactive text modules, participants had to complete an online test at the end of the course. A total of $80 \%$ of the participants claimed their CME credits by taking the test and $71 \%$ of those who took the test passed successfully.

When analysing the results, the clear preference for live lectures from the course participants caused some astonishment (figure 1). Usually, an important benefit of e-learning programmes is thought to be the availability from any place at any time. However, in contrast to this principle, participation in the live lectures necessitated a connection at a fixed time. As the participants' feedback shows, this drawback was more than compensated for by the opportunity to interact with colleagues in real time and to have questions immediately answered by key opinion leaders.

The value of the approaches tested will be used to develop further web-based courses. All the material from the course has been included on the ERS Learning Resources website and can be accessed at www.ers-education.org/asthma

I would like to take this opportunity to thank Dr Pascal Kurosinski, elearning Co-ordinator at the ERS Headquarters, for the hard work he put into this project, for converting all the texts into an appealing and userfriendly interactive html format, and for uploading all presentations onto the ERS elearning website so that they can be accessed by all members.

Based on the experience of the interactive online course on asthma, the ERS School is now looking into developing future courses.

\section{Topics for upcoming web courses}

$\begin{array}{ll}\text { Paediatrics } & \text { In late autumn or early winter } \\ \text { Lung function } & \text { April/May } 2007 \\ \text { Imaging } & \text { To be determined } \\ \text { Sleep } & \text { To be determined } \\ \text { Lung cancer } & \text { To be determined }\end{array}$

